\title{
If Canada needs more doctors, why hasn't medical school enrolment increased?
}

\author{
口 Cite as: CMAJ 2018 October 22;190:E1266-7. doi: 10.1503/cmaj.109-5649
}

Posted on cmajnews.com on Oct. 3, 2018.

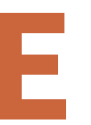
nrolment in Canada's 17 medical schools has remained relatively stable for the past decade, versus a steady rise for more than a decade in the United States, which is nearing a targeted increase of $30 \%$ set by the Association of American Medical Colleges in 2006 to address a projected physician shortage.

So, it might seem that a simple solution to Canada's doctor shortage would be to increase enrolment in medical schools. Provincial governments control enrolment numbers, but most medical schools would welcome the ability to take on more students, according to Dr. Genevieve Moineau, president of the Association of Faculties of Medicine of
Canada. "If a school feels it has the capacity, it would be happy to expand," she says.

The demand is certainly there from prospective students. Dalhousie University, for example, receives between 900 and 1100 applications annually for its 108 first-year positions.

But a shortage of residency positions means any rise in the number of medical students would be counterproductive, as there would be no way to provide the extra graduates with the postgraduate training they need to become practising physicians. "It's very important that provinces ensure that the number of medical school spots is right, but they also have to support them with the appropriate number of residency spots," says Moineau.

In recent years, the number of residency positions available across Canada has fallen. Ontario, for example, has cut 25 positions, says Moineau. For all students to be matched with positions in their desired specialties, a ratio of about $110-120$ positions for every 100 graduates is needed. This was the case until the last few years, says Moineau, but the ratio has since fallen to just 101 positions per 100 grads. This has led to a rise in the number of graduates who cannot find residency positions. "In 2009, there were 11 unmatched graduates," says Moineau. "Last year, it was 169."

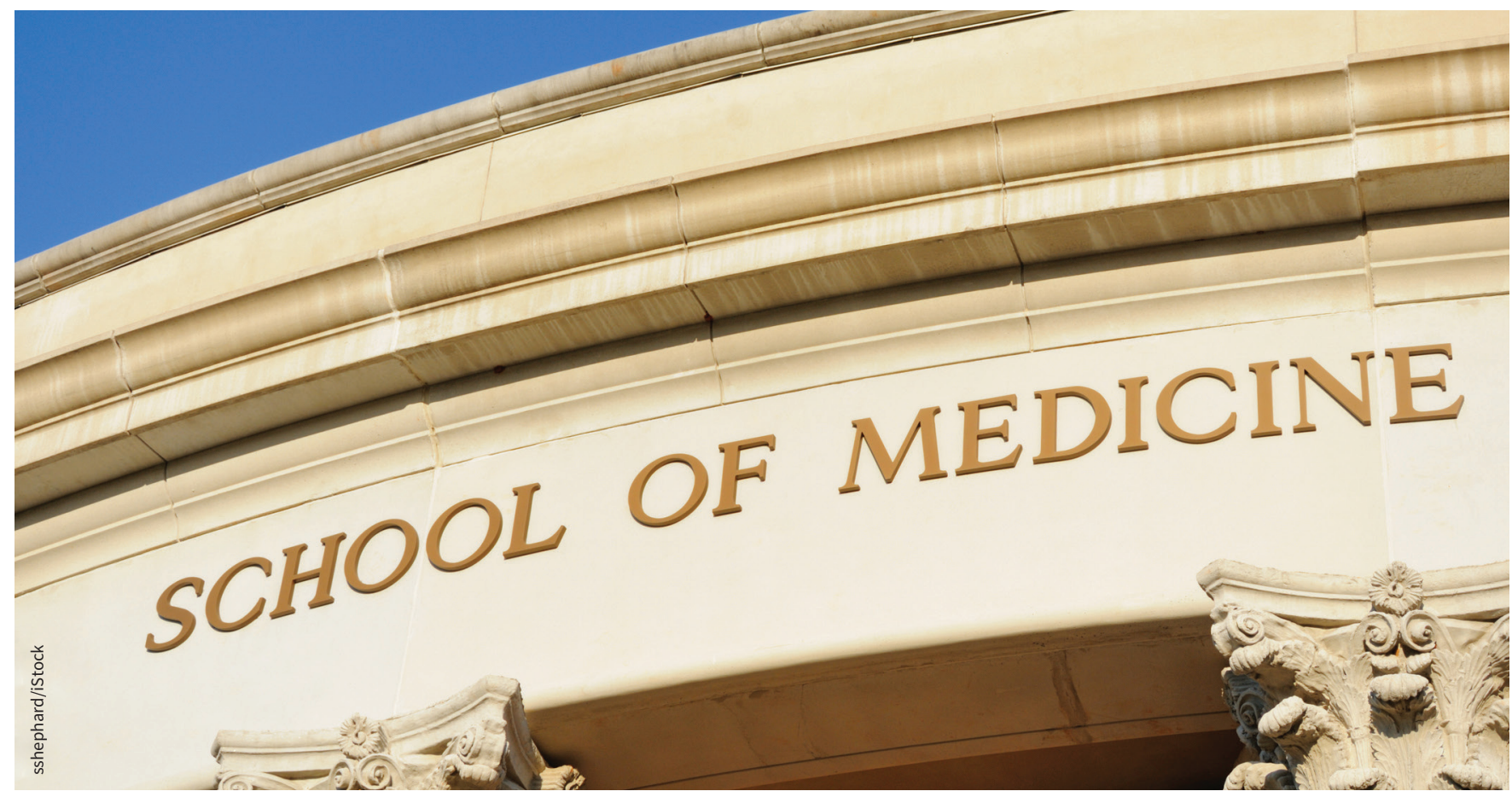

Medical school enrolment has risen in the United States but remained flat in Canada. 
The rise in enrolment numbers in American medical schools' is sparking similar concerns in the US. A survey by the Association of American Medical Colleges found that $78 \%$ of medical school deans are concerned about the ability of incoming students to find residency positions of their choice nationwide. The problem could end up being worse there; unlike in Canada, where provincial governments control the number of residency positions, in the US any hospital can set up a residency program and determine how many residents will be admitted. "It's much more like the Wild West," says Moineau. "You end up with more unfilled positions and unmatched grads."
The problem is not just with the number of positions, but also the types and locations. At the University of British Columbia, for example, about $40 \%$ of residency spots are for family medicine and $60 \%$ for other specialities, says Dr. Shelley Ross, cochair of Doctors of BC's general practice service committee. "That ratio should be the opposite," she says.

What is needed, says Dr. Henry Annan, past-president of the Canadian Federation of Medical Students, is a panCanadian strategy that considers both the number of medical students and the number of residency positions across the country in a socially responsible way. "Now every province does it differently, but doctors are free to move," he says. "The only way to know where and what kind of doctors we need is to have a national system."

The federation has met with federal politicians to request that they begin working with the provinces to develop such a system. "With the increase in unmatched grads, hopefully the need is more apparent," says Annan. If more doctors are needed, the best way to get them is to train more medical students and ensure they have enough residency positions, says Annan. "It takes a long time, but this is the kind of long-term planning we need."

Brian Owens, St. Stephen, NB 